\title{
Improvement in MR and in the dyssynchrony between the mid segments predict super responders in patients undergoing CRT
}

\author{
Miry Blich $^{1 *}$, Shemy Carasso ${ }^{2}$, Mahmoud Suleiman ${ }^{1}$, Ibrahim Marai ${ }^{1}$, Tawfig Zeidan Shwiri ${ }^{1}$, \\ Lior Gepstein ${ }^{1,3}$, Monther Boulos ${ }^{1,3}$ \\ ${ }^{1}$ Division of Pacing and Electrophysiology \\ ${ }^{2}$ Division of Echocardiography, Department of Cardiology, Rambam Health Care Campus and Rappaport Faculty of Medicine \\ ${ }^{3}$ Technion, Haifa, Israel \\ Email: ${ }^{\text {m }}$ blich@rambam.health.gov.il
}

Received 8 April 2012; revised 31 May 2012; accepted 7 June 2012

\begin{abstract}
Background: Twenty to thirty percent of patients with left heart failure in randomized trials do not respond clinically to cardiac resynchronization therapy (CRT). The objectives of our work were to estimate the effectiveness of CRT in our routine practice, and to find predictors of favorable response to CRT. Methods: Retrospective analysis of consecutive patients who underwent CRT from 2003-2007. Results: Fifty six consecutive patients $(73.2 \%$ men, age $66.3 \pm 10.2$ years) with left heart failure (LHF) (ischemic cardiomyopathy $60.7 \%$ ) received CRT and were followed for a mean of 27 months. After the implantation: Mean NYHA improved by one class $(p<0.001)$, LHF admissions were reduced by $79 \%(p<0.0001)$ and mean ejection fruction improved by $31 \%(19.5 \%$ vs $25.6 \%$, p $<0.002$ ). Significant improvement in severity of mitral regurgitation (MR) was an important predictor of high responsiveness $(p=0.004)$. Improvement of MR was associated with complete left bundle branch block (CLBBB) $(p=0.04)$ and lower total mortality $(p=0.005)$. Improvement in synchronization between the mid lateral and mid septal segments, as was calculated with longitudinal strain using echocardiography (105 \pm 38 vs $20 \pm 23$ msec, $p=0.008$ ) was predictor of super responsiveness and reduction in MR among patients with moderate to severe MR prior to implantation. Worsening the delay between the mid posterior and mid anterior septal segments $(21 \pm 27$ vs $120 \pm 0$ msec, $p=$ 0.006) was associated with absence of response and lack of improvement in MR. Conclusions: Patients who improve mid segments dyssynchrony in four chamber view, have more chance to improve MR and to become super responders.
\end{abstract}

${ }^{*}$ Corresponding author.
Keywords: Mitral Regurgitation; Cardiac Resynchronization Therapy

\section{INTRODUCTION}

Cardiac resynchronization therapy (CRT) has been shown to improve symptoms, increase exercise capacity, decrease heart failure hospitalization and decrease mortality in patients with New York Heart Association (NYHA) class 3/4 with depressed systolic function and a prolonged QRS [1-3]. However, $20 \%-30 \%$ of patients who receive CRT therapy do not show significant clinical improvement [4-6]. As a result there has been intense investigation to develop non invasive parameters to predict CRT response [7-9]. While mechanical dyssynchrony assessed in the longitudinal axis of myocardial motion was shown to be predictive in single center trials [7-10]. The multi-center PROSPECT trial failed to identify any echocardiographic dyssynchrony criteria to predict responders better than clinical criteria [11]. Speckle tracking radial strain from routine gray scale $2 \mathrm{D}$ echocardiographic images has been proposed to quantify dyssynchrony and to predict immediate and long term response to CRT [12].

Mitral regurgitation (MR) presents in up to $60 \%$ of patients with chronic left ventricular (LV) dysfunction and is a powerful risk factor for poor clinical outcome despite optimal medical treatment [13-15]. Recent studies have demonstrated that CRT may result in improvement in MR [16,17]. However the mechanism of this improvement in MR following CRT is not yet fully understood. LV dyssynchrony involving the posterior mitral leaflet appeared to be a determinant for the presence of MR [5]. In addition, preliminary data suggested that CRT can acutely reduce MR in patients with dyssynchrony between the papillary muscles [18]. Besides the acute effect, 
reduction in MR has also been shown at long term follow up after CRT and is most likely secondary to LV reverse remodeling $[19,20]$.

The objectives of our work are: 1) To estimate the effectiveness and safety of CRT in our routine practice, outside of clinical trials; 2) To find clinical and echocardiographical predictors of favorable response to CRT; 3 ) To evaluate the role of dyssynchrony in reduction of MR; 4) To determine predictors of significant MR reduction after CRT using the novel approach of 2D longitudinal myocardial strain.

\section{METHODS}

\subsection{Patients and Definition of Response}

We retrospectively studied 56 consecutive patients who underwent CRT in our hospital from February 2003 until December 2007. Clinical parameters were assessed before and after CRT implantation. Median follow up was 22.5 months. At the end of the follow up patients were divided into three groups based on the clinical improvement in NYHA. Patients that didn't improve in NYHA class were defined as non responders. Patients that improved in one class and two classes of NYHA were defined as responders and super responders respectively.

\subsection{Echocardiography}

Echocardiography was performed at rest in the left lateral decubitus position using a variable frequency phased array transducer $(1.9-5 \mathrm{MHz})$ with conventional methods. LV end systolic and end diastolic dimensions and left atrial diameter in end systole were obtained in the parasternal long axis view. LV ejection fraction was measured by the biplane Simpson's method. MR was identified as percent MR jet area in relation to left atrial area (LA) by planimetry and averaged in apical four, two and three chamber views. The severity of MR was graded on a three point scale: mild $=1+($ jet area/LA area $<20 \%$ ), moderate $=2+($ jet area $/ \mathrm{LA}$ area $20 \%-40 \%$ ), severe $=3+$ (jet area/LA area $>40 \%$ ). Diastolic dysfunction was assesed by mitral valve inflow or tissue dopler velocities of the mitral valve, graded on a three point scale: mild $=1+$ (abnormal relaxation), moderate $=2+$ (pseudonormal pattern) and sever $=3+$ (restrictive pattern). LV subendocardial mechanics were analyzed using Velocity Vector Imaging (VVI, Siemens Medical Systems, Mountain View, California), a 2D tissue tracking software. Time to peak longitudinal strain was measured from the apical 2-, 3-, and 4- chamber views (6 segments in each standard view). A time difference between opposing wall segments was calculated for the base and mid levels in each view. All analysis was performed by a single reader. The echocardiographic analysis was blinded to clinical out- come.

\subsection{Statistical Analysis}

Continuous variables are summarized as mean values \pm $\mathrm{SD}$ and categorical variables as a percent of the total. Baseline and follow up variables were compared by the non parametric paired Wilcoxon Signed Ranks test and Marginal Homogeneity test. Baseline and follow up continuous variables were compared between the non responders, responders and super responders by the Kruskal Wallis test and categorical variables by Pearson Chi Square test. Difference between non responders and super responders with severe MR were analyzed by $\chi^{2}$ or Fisher exact test (dichotomous variables) or $t$ test (averages). Cumulative survival was calculated according to improvement in MR after the implantation by the Kaplan- Meier method. All statistical analysis was performed using SPSS version 12(SPSS Inc. Chicago, IL, USA). A $\mathrm{p}$ value $<0.05$ was considered significant.

\section{RESULTS}

\subsection{Patient Characteristics}

Fifty six consecutive patients $(73.2 \%$ men, age $66.3 \pm 9$ years), received CRT and were followed for $27.4 \pm 18.7$ months. Baseline characteristics of the patients included in this study are summarized in Table 1. Five patients were upgraded from pacemaker and five patients from

Table 1. Baseline characteristic of the study population.

\begin{tabular}{ll}
\hline Variable & All patients $(\mathrm{n}=56)$ \\
\hline Male, \% & $73.2 \%$ \\
Age, mean (SD) & $66.3(10.2)$ \\
Hypertension, \% & $64.3 \%$ \\
Diabetes Mellitus ,\% & $48.2 \%$ \\
Ischemic Etiology, \% & $60.7 \%$ \\
CABG, \% & $30.4 \%$ \\
NYHA, mean (SD) & $3(0.6)$ \\
QRS duration > 120 msec, \% & $89.3 \%$ \\
CLBBB, \% & $71.4 \%$ \\
Ejection Fraction, mean (SD) & $19.5(7)$ \\
Grade of MR , mean (SD) & $1.8(0.9)$ \\
Endocardial implantation, \% & $86.2 \%$ \\
Chronic or paroxysmal AF, \% & $28.6 \%$ \\
ACE inhibitors or ARB, \% & $80.4 \%$ \\
Beta blockers, \% & $78.6 \%$ \\
Spironolactone, \% & $53.6 \%$ \\
Diuretics mg/day, mean (SD) & $89.5(51)$ \\
\hline
\end{tabular}

CABG: Coronary artery bypass graft; NYHA: New york heart association; CLBBB: Complete left bundle branch block; MR: Mitral regurgitation; AF: Atrial fibrillation; ACE: Angiotensin converting enzyme; ARB: Angiotensin receptor blocking. 
defibrillator device. Twenty seven patients (48\%) received CRT with defibrillator. Mean number of admissions with heart failure exacerbation per patient per year before CRT implantation was 1.9. Twenty one patients (37.5\%) died during the follow up, ten from heart failure, 2 from arrhythmia and 9 from non cardiac cause.

\subsection{Clinical and Ecocardiographic Parameters after CRT Therapy}

Clinical and echocardiographic parameters pre and post CRT therapy are listed in Table 2. The exact NYHA class after CRT implantation could have been determined for 35 patients. Functional capacity of the rest of the patients was influenced by other medical problems or was not known due to loss of follow up. After CRT implantation 11 patients $(31 \%)$ did not improve NYHA class and were defined as non responders, 15 patients (43\%) improved in one NYHA class and were defined as responders and 9 patients (26\%) improved in 2 NYHA classes and were defined as super responders. Comparison between those three groups regarding variables before CRT implantation and after CRT implantation is presented in Tables 3 and 4 respectively. There was no statistically significant difference between the non responders, responders and super responders regarding the location of the coronary sinus lead at the implantation. No improvement in MR grade after CRT implantation among the non responders $(67 \%$ had moderate to severe MR before and after CRT implantation) as opposed to the super responders, which $88 \%$ of them had moderate to severe MR before CRT implantation and $100 \%$ had only mild MR after CRT implantation. Significant improvement in severity of MR was an important predictor of high responsiveness $(p=0.03)$. Improvement in MR grade was associated with complete left bundle branch block pattern at the baseline ECG $(\mathrm{p}=0.04)$ and lower mortality (Figure 1).

Table 2. Clinical and echocardiographic parameters pre and post CRT implantation.

\begin{tabular}{llll}
\hline Variable & $\begin{array}{l}\text { Pre CRT } \\
\text { implantation }\end{array}$ & $\begin{array}{l}\text { Post CRT } \\
\text { implantation }\end{array}$ & $\mathrm{p}$ \\
\hline NYHA class (mean) & 3 & 2 & $<0.001$ \\
$\begin{array}{l}\text { Number LHF exacerbations } \\
\text { (mean/patient/year) }\end{array}$ & 1.9 & 0.4 & $<0.0001$ \\
$\begin{array}{l}\text { EF \%(mean) } \\
\text { MR moderate or severe \% }\end{array}$ & $64 \%$ & $50 \%$ & $<0.002$ \\
DD (mean) & 2.4 & 1.4 & 0.016 \\
\hline
\end{tabular}

NYHA: New york heart association; LHF: Left heart failure; MR: Mitral regurgitation; EF: Ejection fraction; DD: Diastolic dysfunction.
Table 3. Baseline clinical and echocardiographic parameters pre CRT implantation of responders and non responders.

\begin{tabular}{lcccc}
\hline $\begin{array}{l}\text { Variables before } \\
\text { CRT implantation }\end{array}$ & $\begin{array}{l}\text { Non } \\
\text { Responders } \\
\mathrm{n}=11(31 \%)\end{array}$ & $\begin{array}{l}\text { Responders } \\
\mathrm{n}=15(43 \%)\end{array}$ & $\begin{array}{l}\text { Super } \\
\text { Responders } \\
\mathrm{n}=9(26 \%)\end{array}$ & $\mathrm{p}$ \\
\hline Age, mean & 64.7 & 66.7 & 66.7 & $\mathrm{NS}$ \\
$\begin{array}{l}\text { Male, \% } \\
\text { Ischemic etiology, \% }\end{array}$ & $54 \%$ & $60 \%$ & $55 \%$ & $\mathrm{NS}$ \\
$\begin{array}{l}\text { LHF exacerbation } \\
\text { ( mean/patient/year) }\end{array}$ & 0.8 & 2 & 2.1 & 0.02 \\
$\begin{array}{l}\text { QRS > 120 msec, \% } \\
\text { CLBBB, \% }\end{array}$ & $82 \%$ & $87 \%$ & $89 \%$ & $\mathrm{NS}$ \\
$\begin{array}{l}\text { EF, mean } \\
\begin{array}{l}\text { Echocardiographic } \\
\text { disynchronization, \% }\end{array}\end{array}$ & $73 \%$ & $87 \%$ & $89 \%$ & $\mathrm{NS}$ \\
$\begin{array}{l}\text { MR moderate } \\
\text { or severe, \% }\end{array}$ & $67 \%$ & $20 \%$ & $16 \%$ & $\mathrm{NS}$ \\
$\begin{array}{l}\text { Severe diastolic } \\
\text { dysfunction, \% }\end{array}$ & $75 \%$ & $73 \%$ & $33 \%$ & $\mathrm{NS}$ \\
\hline
\end{tabular}

LHF: Left heart failure; CLBBB: Complete left bundle branch block; EF: Ejection fruction; MR: Mitral regurgitation.

Table 4. Clinical and echocardiographic parameters post CRT implantation of responders and non responders.

\begin{tabular}{lcccc}
\hline $\begin{array}{l}\text { Variables after } \\
\text { CRT implantation }\end{array}$ & $\begin{array}{l}\text { Non } \\
\text { Responders } \\
\mathrm{n}=11(31 \%)\end{array}$ & $\begin{array}{l}\text { Responders } \\
\mathrm{n}=15(43 \%)\end{array}$ & $\begin{array}{l}\text { Super } \\
\text { Responders } \\
\mathrm{n}=9(26 \%)\end{array}$ & $\mathrm{p}$ \\
\hline $\begin{array}{l}\text { LHF exacerbation } \\
\text { (mean/patient/year) }\end{array}$ & 0.5 & 0.4 & 0.1 & $\mathrm{NS}$ \\
$\begin{array}{l}\text { Grade of } \\
\begin{array}{l}\text { MR, mean } \\
\text { Grade of DD, mean }\end{array}\end{array}$ & 2 & 1.7 & 1 & 0.016 \\
$\begin{array}{l}\text { EF, mean } \\
\begin{array}{l}\text { Mortality due } \\
\text { to LHF, } \%\end{array}\end{array}$ & $23.7 \%$ & $26 \%$ & $29 \%$ & $\mathrm{NS}$ \\
\begin{tabular}{l} 
Total mortality, \% \\
\hline
\end{tabular} & $33 \%$ & $20 \%$ & 0 & $\mathrm{NS}$ \\
\end{tabular}

LHF: Left heart failure; MR: Mitral regurgitation; DD: Diastolic dysfunction; EF: Ejection fraction.

\subsection{Predictors of MR Improvement}

Among 13 patients with moderate to severe MR from the non responders and super responders groups, in 9 patients, images for 2D longitudinal strain analysis were available. The echocardiographic parameters and 2D longitudinal strain at baseline and follow up among patients with moderate to severe MR in the non responders versus super responders are presented in Table 5. There was no statistically significant difference between the non responders and super responders with moderate to 


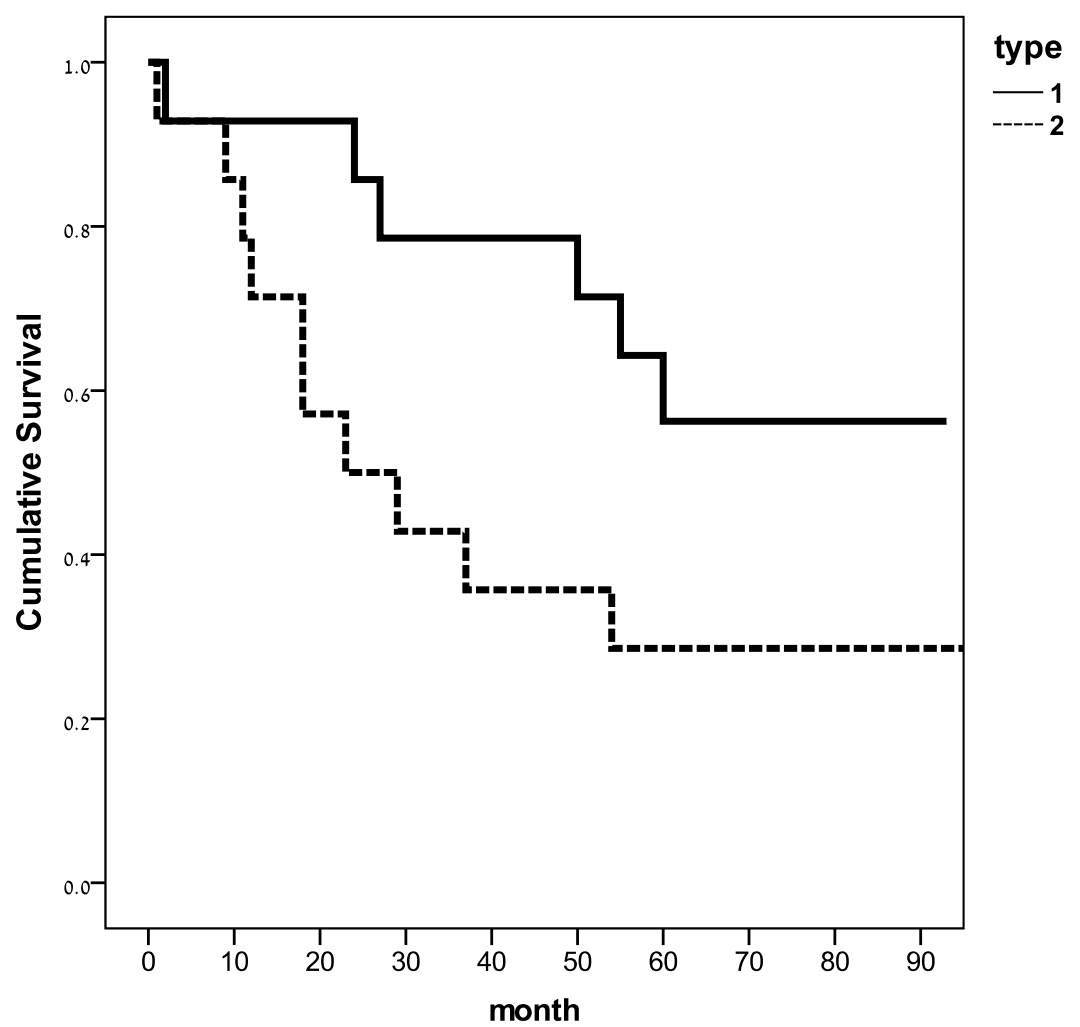

Figure 1. Cumulative survival, according to improvement in mitral regurgitation (MR) after implantation. Group 1 (solid line) MR improved at list in one grade. Group 2 (dot line), no improvement in MR after implantation $(\mathrm{p}=0.04)$.

Table 5. Comparison of echo parameters and 2D longitudinal strain pre and post CRT between patients with severe MR non responders and super responders.

\begin{tabular}{|c|c|c|c|c|c|c|c|c|}
\hline \multirow[t]{2}{*}{ Variable } & \multicolumn{3}{|c|}{ Non responders $(n=5)$} & \multicolumn{3}{|c|}{ Super responders $(n=4)$} & \multicolumn{2}{|c|}{$\begin{array}{l}\text { p (non responders } \\
\text { versus super responders) }\end{array}$} \\
\hline & Pre & Post & $\mathrm{p}$ & Pre & Post & $\mathrm{p}$ & Pre & Post \\
\hline LVEDV (4ch), ml & $177 \pm 8$ & $160 \pm 41$ & $\mathrm{~N} / \mathrm{S}$ & $148 \pm 18$ & $100 \pm 29$ & 0.02 & 0.05 & 0.06 \\
\hline LVESV (4ch), ml & $143 \pm 22$ & $143 \pm 13$ & $\mathrm{~N} / \mathrm{S}$ & $107 \pm 13$ & $67 \pm 26$ & 0.03 & 0.06 & 0.006 \\
\hline LVEDD (short), cm & $5.5 \pm 0.5$ & $5.8 \pm 0.7$ & $\mathrm{~N} / \mathrm{S}$ & $5.3 \pm 0.3$ & $4.4 \pm 0.9$ & $\mathrm{~N} / \mathrm{S}$ & $\mathrm{N} / \mathrm{S}$ & 0.06 \\
\hline LVEDD (long), cm & $8.7 \pm 1.1$ & $7.9 \pm 0.7$ & $\mathrm{~N} / \mathrm{S}$ & $8.5 \pm 0.6$ & $7.9 \pm 0.7$ & $\mathrm{~N} / \mathrm{S}$ & $\mathrm{N} / \mathrm{S}$ & $\mathrm{N} / \mathrm{S}$ \\
\hline Ec Jet D, (3ch) & Ec 2/5 & Ec 2/5 & $\mathrm{N} / \mathrm{S}$ & Ec $1 / 4$ & $0 / 4$ & $\mathrm{~N} / \mathrm{S}$ & $\mathrm{N} / \mathrm{S}$ & $\mathrm{N} / \mathrm{S}$ \\
\hline TPL & $2 / 5$ & $2 / 5$ & $\mathrm{~N} / \mathrm{S}$ & $2 / 4$ & $2 / 4$ & $\mathrm{~N} / \mathrm{S}$ & $\mathrm{N} / \mathrm{S}$ & $\mathrm{N} / \mathrm{S}$ \\
\hline Ring D (2ch), cm & $2.9 \pm 0.2$ & $2.9 \pm 0.9$ & $\mathrm{~N} / \mathrm{S}$ & $2.5 \pm 0.7$ & $2.6 \pm 0.5$ & $\mathrm{~N} / \mathrm{S}$ & $\mathrm{N} / \mathrm{S}$ & $\mathrm{N} / \mathrm{S}$ \\
\hline $\mathrm{A} / \mathrm{P} \mathrm{PM}, \mathrm{cm}$ & $4.2 \pm 0.4 / 4.5 \pm 0.2$ & $4.7 \pm 0.6 / 4.4 \pm 0.3$ & $\mathrm{~N} / \mathrm{S}$ & $5.2 \pm 0.8 / 4.8 \pm 0$ & $43.9 \pm 0.8 / 4.4 \pm 0.8$ & $\mathrm{~N} / \mathrm{S}$ & $\mathrm{N} / \mathrm{S}$ & $\mathrm{N} / \mathrm{S}$ \\
\hline $\mathrm{A} / \mathrm{P}$ Chorda, cm & $2.3 \pm 0.5 / 2.8 \pm 0.07$ & $72.6 \pm 0.2 / 2.6 \pm 0.15$ & $5 \mathrm{~N} / \mathrm{S}$ & $2.8 \pm 1 / 2.7 \pm 1$ & $2.3 \pm 0.3 / 3.3 \pm 0.5$ & $\mathrm{~N} / \mathrm{S}$ & $\mathrm{N} / \mathrm{S}$ & $0.06 / \mathrm{N} / \mathrm{S}$ \\
\hline$\Delta$ Strain mid (4ch) & $182 \pm 121$ & $130 \pm 53$ & $\mathrm{~N} / \mathrm{S}$ & $105 \pm 38$ & $20 \pm 23$ & 0.008 & $\mathrm{~N} / \mathrm{S}$ & 0.006 \\
\hline$\Delta$ Strain base (4ch) & $236 \pm 102$ & $192 \pm 86$ & $\mathrm{~N} / \mathrm{S}$ & $125 \pm 133$ & $70 \pm 90$ & $\mathrm{~N} / \mathrm{S}$ & $\mathrm{N} / \mathrm{S}$ & $\mathrm{N} / \mathrm{S}$ \\
\hline$\Delta$ Strain mid (2ch) & $136 \pm 98$ & $100 \pm 141$ & $\mathrm{~N} / \mathrm{S}$ & $46 \pm 51$ & $40 \pm 56$ & $\mathrm{~N} / \mathrm{S}$ & $\mathrm{N} / \mathrm{S}$ & $\mathrm{N} / \mathrm{S}$ \\
\hline$\Delta$ Strain base (2ch) & $60 \pm 28$ & $80 \pm 57$ & $\mathrm{~N} / \mathrm{S}$ & $60 \pm 55$ & $70 \pm 61$ & $\mathrm{~N} / \mathrm{S}$ & $\mathrm{N} / \mathrm{S}$ & $\mathrm{N} / \mathrm{S}$ \\
\hline$\Delta$ Strain mid (3ch) & $21 \pm 27$ & $120 \pm 0$ & 0.006 & $27 \pm 33$ & $40.5 \pm 47$ & $\mathrm{~N} / \mathrm{S}$ & $\mathrm{N} / \mathrm{S}$ & 0.03 \\
\hline$\Delta$ Strain base (3ch) & $40 \pm 40$ & $100 \pm 28$ & $\mathrm{~N} / \mathrm{S}$ & $69 \pm 68$ & $50 \pm 50$ & $\mathrm{~N} / \mathrm{S}$ & $\mathrm{N} / \mathrm{S}$ & $\mathrm{N} / \mathrm{S}$ \\
\hline
\end{tabular}

LVEDV: Left ventricle end Diastolic volume; LVESV: Left ventricle end systolic volume; LVEDD: Left ventricle end diastolic diameter; LVESD: Left ventricle end systolic diameter; Ec jet D: Eccentric jet direction; TPL: Tethering of post leaflet; Rind D: Ring diameter; A/P PM: Length of ant and post papillary muscle; A/P chorda: Length of ant and post chorda; $\Delta$ strain: Difference in peak strain time between the segments. 
severe MR, regarding echocardiographic parameters as MR jet direction, tethering of posterior leaflet, ring diameter and the length of anterior and posterior papillary muscle or chorda pre CRT implantation. Improvement in synchronization between the mid lateral and mid septal segments $(130 \pm 53 \mathrm{msec}$ vs. $20 \pm 23 \mathrm{msec}, \mathrm{p}=0.006)$ and between the mid anteroseptal and mid post segments $(120 \pm 0 \mathrm{msec}$ vs. $40.5 \pm 47 \mathrm{msec}, \mathrm{p}=0.03)$, as was calculated with longitudinal strain was predictor of super responders. Worsening the delay between the mid posterior and mid anterior septal segments was associated with absence of response $(21 \pm 27 \mathrm{msec}$ vs $120 \pm 0 \mathrm{msec}$, $\mathrm{p}=0.006)$.

\section{DISCUSSION}

As was demonstrated in the randomized clinical trials, we have shown (Table 2) that CRT is an effective therapy in long term follow up of symptomatic patients with left heart failure in real world practice (69\% responders). In our population, $25 \%$ of the patients treated with CRT can be identified as super- responders. This proportion is similar to previously reported results [21,22]. Significant improvement in severity of MR was an important predictor of high responsiveness $(p=0.03)$.

Multiple factors such as LV remodeling, increased leaflet tenting area, coaptation height and altered leaflet tethering geometry are considered to cause functional MR in patients with LV systolic dysfunction [18,23,24]. The presence of dyssynchrony is an important contributing factor for worsening MR in patients with LHF $[20,25,26]$. A number of studies have shown that CRT can reduce MR by improving the tethering forces on the papillary muscles consequently improving the global LV function and decreasing the systolic tenting area [20,25]. In addition to these acute changes, reverse LV remodeling and further improvement in LV function occur over time and lead to a better leaflet coaptation [17,27]. Kanzaki et al used tissue Doppler longitudinal strain imaging and demonstrated that improvement in timing of mechanical activation of the papillary muscles after CRT led to an immediate reduction in MR [25]. Similarly Brandt et al showed deterioration of MR after temporary interruption of long term CRT suggesting that mechanical dyssynchrony contributed to this acute MR recurrence [28]. Thus those preliminary results strongly suggest the beneficial role of CRT in functional MR improvement in both ischemic and non ischemic cardiomyopathy $[20,25]$. Even though, nearly $70 \%$ of nonresponders in our work were left with moderate MR after CRT (as opposed to super responders which 100\% had mild MR after CRT). When we compared non responders with moderate to severe MR to super responders with moderate to severe MR, we demonstrated the importance of the delay between mid segments (lateral vs. septal and post vs. ant septal) pre CRT and improvement in the delay after CRT as strong predictor for MR improvement and super responsiveness. Naqvi et al. also found that delayed time to peak strain in the mid inferior segment as predictors of MR reduction [27]. The mid segments represent the areas of insertion of the papillary muscle. Thus reduction in MR severity can be attributed to resynchronized papillary muscle activation and reduced mitral leaflet tethering forces. Super responders also showed improvement in LV end systolic volume which represents LV reverse remodeling leading to reduction in mitral annular size with restoration of mitral valve closure. Future target studies are warranted to further elucidate the role of dyssynchrony in functional MR.

\section{CONCLUSION}

CRT is an effective therapy in long term follows up of symptomatic patients with LHF in real world practice. In patients with significant $\mathrm{MR}$, the presence of significant delay between the mid segments as measured by longitudinal strain in 3 chamber view pre CRT and the improvement in the synchronization in mid segments as measured in 3 and 4 chamber view, were found to be important predictors of improvement in MR and super responsiveness post CRT. Our study suggests that the most important mechanism of MR pre CRT may be related to the dyssynchronization of the mid segments, papillary muscle insertion sites. Understanding the mechanism of MR in each LHF patient and the role of mechanical dyssynchrony as a pathophysiological determinant of MR will allow better selection of patients for CRT.

\section{LIMITATIONS}

The main limitations of this study are its retrospective nature and a small number of patients. In our study for the longitudinal strain analysis we included patients in whom the images were acquired with appropriate frame rates and had good quality. This is the reason that the number of patients was small. We did not evaluate MR by PISA method; however we quantified MR by planimetry in all three apical views before and after CRT and the patients acted as self controls, so the percent reduction in MR should generally not be affected by our methodology for assessment of MR severity.

\section{REFERENCES}

[1] Cazeau, S., Leclercq, C., Lavergne, T., Walker, S., Varma, C., Linde, C. and Garrigue, S. (2001) Multisite stimulation in cardiomyopathies (MUSTIC) study investigators: Effects of multisite biventricular pacing in patients with heart failure and intraventricular conduction 
delay. The New England Journal of Medicine, 344, 873880. doi:10.1056/NEJM200103223441202

[2] Bradley, D.J., Bradley, E.A., Baughman, K.L., Berger, R.D., Calkins, H., Good-man, S.N, Kass, D.A., et al. (2003) Cardiac resynchronization and death from progressive heart failure: A Meta analysis of randomized controlled trials. JAMA, 289, 730-740. doi:10.1001/jama.289.6.730

[3] Cleland, J.G., Daubert, J.C., Erdmann, E., Freemantle, N., Gras, D., Kappenberger, L. and Tavazzi, L. (2005) The effect of cardiac resynchronization on morbidity and mortality in heart failure. The New England Journal of Medicine, 352, 1539-1549. doi:10.1056/NEJMoa050496

[4] Linde, C., Abraham, W.T., Gold, M.R., St John Sutton, M., Ghio, S. and Daubert, C. (2008) Randomized trial of cardiac resynchronization in mildly symptomatic heart failure patients and in asymptomatic patients with left ventricular dysfunction and previous heart failure symptoms. Journal of the American College of Cardiology, 52, 1834-1843. doi:10.1016/j.jacc.2008.08.027

[5] Abraham, W.T., Fisher, W.G., Smith, A.L., Hayes, D.L., Ellestad, M., Trupp, R.J., Underwood, J., et al. (2002) MIRA CLE study group. Multicenter insync randomized clinical evaluation: Cardiac resynchronization in chronic heart failure. The New England Journal of Medicine, 346, 1845-1853. doi:10.1056/NEJMoa013168

[6] Bristow, M.R., Saxon, L.A., Boehmer, J., Krueger, S., Kass, D.A., DeVries, D.W., Feldman, A.M. and Comparison of Medical Therapy, Pacing and Defibrillation in Heart Failure (COMPANION) Investigators (2004) Cardiac resynchronization therapy with or without an implantable defibrillator in advanced chronic heart failure. The New England Journal of Medicine, 350, 2140-2150. doi:10.1056/NEJMoa032423

[7] Yu, C.M., Zhang, Q., Fung, J.W., Chan, H.C., Chan, Y.S., Yip, G.W., Kong, S.L., et al. (2005) A novel tool to assess systolic asynchrony and identify responders of cardiac resynchronization therapy by tissue synchronization imaging. Journal of the American College of Cardiology, 45, 677-684. doi:10.1016/j.jacc.2004.12.003

[8] Penicka, M., Bartunek, J., De Bruyne, B., Vanderheyden, M., Goethals, M., DeZutter, M., Brugada, P., et al. (2004) Improvement of left ventricular function after cardiac resynchronization therapy is predicted by tissue Doppler imaging echocardiography. Circulation, 109, 978-983. doi:10.1161/01.CIR.0000116765.43251.D7

[9] Bax, J.J., Bleeker, G.B., Marwick, T.H., Molhoek, S.G., Boersma, E., Steendijk, P., van der Wall, E.E., et al. (2004) Left ventricular dyssynchrony predicts response and prognosis after cardiac resynchronization therapy. Journal of the American College of Cardiology, 44, 18341840. doi:10.1016/i.jacc.2004.08.016

[10] Yu, C.M., Chau, E., Sanderson, J.E., Fan, K., Tang, M.O., Fung, W.H., Lin, H., et al. (2002) Tissue Doppler echocardiographic evidence of reverse remodeling and improved synchronicity by simultaneously delaying regional contraction after biventricular pacing therapy in heart failure. Circulation, 105, 438-445. doi:10.1161/hc0402.102623
[11] Chung, E.S., Leon, A.R., Tavazzi, L., Sun, J.P., Nihoyannopoulos, P., Merlino, J., Abraham, W.T., et al. (2008) Results of the predictors of response to CRT (PROSPECT) trial. Circulation, 117, 2608-2616. doi:10.1161/CIRCULATIONAHA.107.743120

[12] Suffoletto, M.S., Dohi, K., Cannesson, M., Saba, S. and Gorcsan, J. (2006) Novel speckle tracking radial strain from routine black and white echocardiographic images to quantify dyssynchrony and predict response to cardiac resynchronization therapy. Circulation, 113, 960-968. doi:10.1161/CIRCULATIONAHA.105.571455

[13] Robbins, J.D., Maniar, P.B., Cotts, W., Parker, M.A., Borow, R.O. and Gheorghiade, M. (2003) Prevalence and sevirity of mitral regurgitation in chronic systolic heart failure. Journal of the American College of Cardiology, 91, 360-362. doi:10.1016/S0002-9149(02)03172-7

[14] Grigioni, F., Enriquez-Sarano, M., Zehr, K.J., Bailey, K.R. and Tajik, A.J. (2001) Ischemic mitral regurgitation: Long term outcome and prognostic implication with quantitative doppler assessment. Circulation, 103, 1759-1764. doi:10.1161/01.CIR.103.13.1759

[15] Capomolla, S., Febo, O., Gnemmi, M., Riccardi, G., Opasich, C., Caporotondi, A., Morata, A., et al. (2000) Beta blockade therapy in chronic heart failure: Diastolic function and mitral regurgitation improvement by carvedilol. American Heart Journal, 139, 596-608. doi:10.1016/S0002-8703(00)90036-X

[16] Haan, C.K., Cabral, C.I., Conetta, D.A., Coombs, L.P. and Edwards, F.H. (2004) Selecting patients with mitral regurgitation and left ventricular dysfunction for isolated mitral valve surgery. The Annals of Thoracic Surgery, 78, 820-825. doi:10.1016/j.athoracsur.2004.04.003

[17] Linde, C., Leclercq, C., Rex, S., Garrigue, S., Lavergne, T., Cazeau, S., McKenna, W., et al. (2002) Long term benefits of biventricular pacing in congestive heart failure: Results from the Multisite Stimulation in Cardiomyopathy (MUSTIC) study. Journal of the American College of Cardiology, 40, 111-118. doi:10.1016/S0735-1097(02)01932-0

[18] St John Sutton, M.G., Plappert, T., Abraham, W.T., Smith, A.L., DeLurgio, D.B., Leon, A.R., Loh, E., Multicenter InSync Randomized Clinical Evaluation (MIRACLE) Study Group, et al. (2003) Effect of cardiac resynchronization therapy on left ventricular size and function in chronic heart failure. Circulation, 107, 1985-1990. doi:10.1161/01.CIR.0000065226.24159.E9

[19] Zanon, F., Aggio, S., Baracca, E., Bilato, C., Corbucci, G., Rigatelli, G. and Zonzin, P. (2004) Reduced mitral regurgitation in heart failure patients submitted to cardiac resynchronization therapy: A short term prospective study. Italian Heart Journal, 111, 826-830.

[20] Breithardt, O.A., Sinha, A.M., Schwammenthal, E., Bidaoui, N., Markus, K.U., Franke, A. and Stellbrink, C. (2003) Acute effects of cardiac resynchronization therapy on functional mitral regurgitation in advanced systolic heart failure. Journal of the American College of Cardiology, 41, 765-767. doi:10.1016/S0735-1097(02)02937-6

[21] Castellant, P., Fatemi, M., Bertault-Valls, V., Etienne, Y. and Blanc, J.J. (2008) Cardiac resynchronization therapy: 
"Nonresponders" and "hyperresponders". Heart Rhythm, 5, 193-197. doi:10.1016/j.hrthm.2007.09.023

[22] Gasparini, M., Regoli, F., Ceriotti, C., Galimberti, P., Bragato, R., De Vita, S., Pini, D., et al. (2008) Remission of left ventricular systolic dysfunction and of heart failure symptoms after cardiac resynchronization therapy: Temporal pattern and clinical predictors. American Heart Journal, 155, 507-514. doi:10.1016/j.ahj.2007.10.028

[23] Lai, D.T., Tibayan, F.A., Myrmel, T., Timek, T.A., Dagum, P., Daughters, G.T., Liang, D., et al. (2002) Mechanistic insights into posterior leaflet inter scallop malcoaptation during acute ischemic mitral regurgitation. Circulation, 106, 140-145.

[24] Otsuji, Y., Handschumacher, M.D., Schwammenthal, E., Jiang, L., Song, J.K., Guerrero, J.L., Vlahakes, G.J., et al. (1997) Insights from three dimentional echocardiography into the mechanism of functional mitral regurgitation: Direct in vivo demonstration of altered leaflet thethering geometry. Circulation, 96, 1999-2008. doi:10.1161/01.CIR.96.6.1999

[25] Kanzaki, H., Bazaz, R., Schwartzman, D., Dohi, K., Sade, L..E, Gorcsan, J. 3rd. (2004) A mechanism for immediate reduction in mitral regurgitation after cardiac resynchronization therapy: Insights from mechanical activation strain mapping. Journal of the American College of Cardiology, 44, 1619-1625. doi:10.1016/j.jacc.2004.07.036

[26] Agricola, E., Oppizzi, M., Galdersi, M., Pisani, M., Meris, A., Pappone, C. and Margonato, A. (2006) Role of regional mechanical dyssynchrony as a determinant of functional mitral regurgitation in patients with left ventricular systolic dysfunction. Heart, 92, 1390-1395. doi:10.1136/hrt.2005.082115

[27] Naqvi, T.Z., Rafique, A.M., Swerdlow, C., Verma, S., Siegel, R.J., Tolstrup, K., Kerwin, W., et al., (2008) Predictors of reduction in mitral regurgitation in patients undergoing cardiac resynchronization treatment. Heart, 94, 1580-1588. doi:10.1136/hrt.2007.118356

[28] Brandt, R.R., Reiner, C., Arnold, R., Sperzel, J., Pitschner, H.F. and Hamm, C.W. (2006) Contractile response and mitral regurgitation after temporary interruption of long term cardiac resynchronization therapy. European Heart Journal, 27, 187-192. doi:10.1093/eurheartj/ehi558 